\title{
Development of Gas Chromatographic Method with Electron Capture Detector for Determination of Some PCDDs in Wheat and Rice Grain Matrix
}

\author{
Iffat Abdul Tawab Khan ${ }^{1}$, Qurrat-ul-Ain ${ }^{* 2}$ and Zahida Tasneem Maqsood ${ }^{2}$ \\ ${ }^{I}$ Department of Chemistry, Federal Urdu University of Arts, Science and Technology, \\ Gulshan-e-Iqbal Campus, Karachi-75300, Pakistan. \\ ${ }^{2}$ Department of Chemistry, University of Karachi, Karachi-75270, Pakistan. \\ *Corresponding Author Email: qurrat_chem@uok.edu.pk \\ Received 02 September 2018, Revised 06 May 2019, Accepted 13 May 2019
}

\begin{abstract}
This study develops a gas chromatographic method coupled to micro-electron capture detector to determine four basic polychlorinated dibenzo- $p$-dioxins (PCDDs) congeners: 1, 1,2,3,7,8pentachlorodibenzo- $p$-dioxin; 2, 2,3,7,8-tetrachlorodibenzo- $p$-dioxin; 3, 1,2,3,6,7,8-hexachlorodibenzo-p-dioxin; and 4, 1,2,3,4,6,7,8-heptachlorodibenzo- $p$-dioxin in wheat and rice. The PCDDs were extracted using 1:1 acetone: $n$-hexane mixture followed by cleaning with acidic aluminium oxide in polypropylene mini columns and eluted with dichloromethane. In quantitative determinations, the limit of detection for congener 1 of PCDDs was $0.4 \mathrm{ng} \mathrm{mL}^{-1}$ while for other congeners (2-4) it was found to be $1.0 \mathrm{ng} \mathrm{mL}^{-1}$. The congener 1 was checked at spiking levels of $0.02,0.05$ and $0.1 \mathrm{ng} \mathrm{g}^{-1}$, and its recovery was $85.96-120.74 \%$ and $95.32-116.88 \%$ from wheat and rice, respectively. Wheat and rice were also spiked by congers $2-4$ at spiking levels of 0.05 , 0.1 and $0.5 \mathrm{ng} \mathrm{g}^{-1}$; the recovery ranges from wheat were $87.70-115.54 \%, 85.64-117.88 \%$ and $88.40-119.32 \%$ for congener 2,3 and 4 , respectively, while from rice the recovery was $77.67-$ $115.68 \%, 83.18-119.68 \%$ and $79.76-131.15 \%$ for congener 2,3 and 4 , respectively. The limit of quantification was determined as $0.1 \mathrm{ng} \mathrm{g}^{-1}$ for congener 1 and $0.5 \mathrm{ng} \mathrm{g}^{-1}$ for other three PCDDs (2-4). The intra-day and inter-day RSDs of peak areas $(n=3)$ for four congeners $\left(2 \mathrm{ng} \mathrm{mL}{ }^{-1}\right)$ were ranged at $2.5-8.1 \%$ and $3.1-10.6 \%$, respectively. This study provides a simple and cost-effective gas chromatographic-electron capture detector method to study some basic PCDDs in wheat and rice grains first time in Pakistan with fair precision and accuracy when expensive high resolution gas chromatographic-mass spectrometry method is not accessible.
\end{abstract}

Keywords: GC- $\mu-E C D$, Congeners of PCDDs, Limit of detection (LOD), Spiking levels, Recovery percent, Limit of quantification (LOQ)

\section{Introduction}

Wheat and rice are the two most important cereal grains, constituting our main diet. Polychlorinated dibenzo- $p$-dioxins (PCDDs) can contaminate food grains and other food products through their entrance in food chain. The PCCDs mainly accumulate in high fat food due to their high lipophilicity. About $90 \%$ human exposure to PCDDs is ascribed to consumption of contaminated food [1-4]. The PCCDs are released in the environment in small amounts mainly as unintentional byproducts of anthropogenic activities (steel manufacturing, iron sintering, waste incineration, etc.) or processes such as forest fires, which specifically involve organic chlorine or inorganic chlorides $[5,6]$.

The PCDDs belong to highly harmful class of organic compounds called 'persistent organic pollutants (POPs)', extremely resistant to biological, chemical, and photolytic degradation. 
The PCDDs-induced toxicity includes skin lesions (e.g., chloracne), endometriosis, teratogenic effects, reproductive effects and carcinogenicity to living organisms $[1,7]$. Out of two hundred ten possible congeners of PCDDs, at least 17 have been identified with broad range toxicity, and 2,3,7,8-tetrachlorodibenzo- $p$-dioxin is recognized with highest toxicity among them [5]. Twelve different POPs including PCDDs have been known to be removed and controlled by 150 countries under Stockholm Convention treaty [3]. The recommended tolerable/allowable daily intake (TDI/ADI) value for PCDDs is $4 \mathrm{pg}-\mathrm{TEQ} / \mathrm{kg} / \mathrm{day}$ $[7,8]$, while tolerable weekly intake (TWI) from the European Community (EC) is 14 pg WHO$\mathrm{TEQ} / \mathrm{kg} /$ week. TEQ value represents total toxic equivalence for PCDDs mixtures present in various matrices. The TEQ is the sum of products of the individual congener concentrations and TEFs (toxic equivalence factors).

The insight and control of biochemical and chemical risks of dioxins in food has been comprehensively reviewed by various researchers $[1,7,9,10]$. The impact of cooking processes on total concentrations of PCDDs has been assessed by Perello et al. in various common food stuffs in Spain [11]. PCDDs have been detected in different food items under several monitoring programs carried out in several countries such as China [5], Japan [12], Italy [13], Kuwait [14], United States [15], Germany [16], Canada [17], France [18], Egypt [19], Spain [20] and Greece [21]. Huang et $a l$. estimated potential influence of dietary patterns changes (i.e., decreasing vegetable and total grain consumption and increasing animal-derived food intake) on Chinese population health risk (increasing cancer risk) to dioxins [22]. McCrady et al. [23] and Uegaki et al. [24] examined the pathways of the PCDDs in food chain through grains. Otani et al. also investigated the dioxins levels in food grains and some beans [8]. Therefore, it is necessary to acquire information on residual levels of PCCDs in food and feed to evaluate their health importance.

Various extraction, clean-up and detection techniques for PCDDs in different matrixes have been developed and reported so far [25-28]. Some efficient quantification techniques to determine toxicity levels of PCDDs include high resolution gas chromatography-high resolution mass spectrometry (HRGC-HRMS), GC-tandem mass spectrometry (GC-QITMS/MS), GC-triple quadrupole mass spectrometry (GC-QQQMS/MS) and GC-Fourier transform ion cyclortron resonance mass spectrometry (GC-FTICRMS) [1]. The HRGC-HRMS is recognized as the confirmatory tool for PCDDs analysis due to its excellent sensitivity and selectivity. However, the very high cost of HRGC-HRMS operation, maintenance and instrument itself demand researchers to develop alternative approaches with reduced analysis costs for dioxins [5]. Particularly in Pakistan, it is very difficult at present to conduct monitoring of PCDDs due to the unavailability of up-to-date and highly sensitive techniques intended for their clean-up and quantification. Thus, only few studies have been reported for Pakistan on dioxins monitoring, including dioxins level studies in chicken eggs [29], human milk [30], animal milk [31] and river sediments [32]. The study of International POPs Elimination Network (2005) observed exceeding dioxins levels in the eggs from Peshawar compared to newly proposed European Union (EU) action level, supporting the need for further monitoring in all environment compartments, particularly in food and long-term changes to reduce PCDDs releases into the Pakistani environment [29]. For proper monitoring of PCDDs in Pakistan, first there is a prerequisite of developing multiple detection system for all dioxins congeners.

Therefore, the aim of current study is to develop a systematic method to analyze few basic PCDDs in food samples. In this regards, wheat and rice grains have been selected to study four different congeners of PCDDs, 1,2,3,7,8pentachloroDD (1), 2,3,7,8-tetrachloroDD (2), 1,2,3,6,7,8-hexachloroDD (3) and 1,2,3,4,6,7,8heptachloroDD (4). To our knowledge, no systematic data has been reported so far on using gas chromatographic-micro-electron capture detector (GC- $\mu-E C D)$ method to determine PCDDs in food grains in particular in Pakistan. Therefore, samples of wheat and rice were monitored for a mixture of selected PCDDs congeners using GC- $\mu$ ECD to develop a method of their analysis in food 
grains, and the performance and feasibility of method was evaluated and discussed.

\section{Materials and Methods Chemicals}

Solvents ( $n$-hexane, dichloromethane and acetone) were obtained from Tedia Company (USA), and they were of chromatographic grade. Analytical grade alumina $\left(\mathrm{Al}_{2} \mathrm{O}_{3}, \mathrm{pH} 4.5\right.$, activity 1) and anhydrous sodium sulphate $\left(\mathrm{Na}_{2} \mathrm{SO}_{4}\right)$ were procured from Merck (Darmstadt, Germany). Acidic alumina was heated to $450{ }^{\circ} \mathrm{C}$ for $3 \mathrm{~h}$ to activate prior to analysis, and anhydrous sodium sulphate was heated to $150{ }^{\circ} \mathrm{C}$ for $3 \mathrm{~h}$ to dry and stored in a desiccator before use. PCDDs congeners 1-4 $\left(50 \mu \mathrm{gmL}^{-1}\right)$ were obtained from Wellington laboratories (Canada). $n$-Hexane was used to prepare separate stock standard PCDDs solutions $\left(10 \mu \mathrm{gmL}^{-1}\right)$ in $5 \mathrm{~mL}$. An intermediate mixed standard solution of four congeners $(0.2$ $\mu \mathrm{gmL}^{-1}$ each) and the calibration working standard mixtures (containing four congeners) in the equivalent concentration range of $0.1-160 \mathrm{ngmL}^{-1}$ were prepared by further dilutions in $100 \mathrm{~mL}$ to determine linearity (Table 1). The working standard mixtures of PCDDs congeners 1-4 for spiking were separately prepared in $n$-hexane from the stock standard solutions as per requirement (Table 2) to determine \% recoveries of congeners. The stock and working standards were prevented from light and stored at $4^{\circ} \mathrm{C}$. Under prescribed storage conditions, all the solutions were stable for at least one month.

\section{Instruments and $G C-\mu-E C D$ conditions}

An Agilent technologies $6890 \mathrm{~N}$ (USA) gas chromatograph was coupled to $\mathrm{Ni}^{63} \mu$-ECD. An HP-5MS capillary column $(30 \mathrm{~m}, 0.25 \mu \mathrm{m}$ film thickness, $0.25 \mathrm{~mm}$ id) and 7683 series auto injector were equipped to GC system. The injection mode was splitless. For data collection, the system was provided with a software enhanced data analysis. The operating temperature conditions were adjusted as follows: injector 280 ${ }^{\circ} \mathrm{C}$, column oven $250{ }^{\circ} \mathrm{C}$ and detector $300{ }^{\circ} \mathrm{C}$. Nitrogen (purity 99.9995\%) with a flow rate of 0.5 $\mathrm{mL} \min ^{-1}$ was operated as a carrier gas, while 60 $\mathrm{mL} \min ^{-1}$ of nitrogen was adjusted as makeup flow.
A Buchi V-512 Model (Switzerland) rotary evaporator with chiller and Dynac (USA) centrifuge machine were also used.

\section{Sample collection and preparation}

Cereal grain (wheat and rice) samples were investigated for PCDDs to verify $\mathrm{GC}-\mu-\mathrm{ECD}$ instrument performance using previously reported methods of pesticide analysis in grains with some modifications [33]. All procedures were applied to wheat and rice grains separately. One $\mathrm{kg}$ of rice and wheat samples were acquired from a local market of Gulshan-e-Iqbal Town (Karachi), initially cultivated and refined in Larkana city before transport to Karachi. Each sample was ground in a laboratory mill, sieved using a 40mesh size sieve, and used as a control. Each experiment was performed in triplicate. To $5 \mathrm{~g}$ of ground grain sample, a mixture of PCDDs congeners (1-4) was added in specified amount (Table 2) and agitated for 5 minutes. This spiked sample was kept on standing for three hours for complete absorption of the congeners. The spiked samples and control (the congener free sample) were then allowed to pass through the following extraction and clean-up procedures before $\mathrm{GC}-\mu$ ECD instrumental analysis.

\section{Extraction process}

For extraction, the spiked or control grain sample was transferred to a centrifuge tube of 100 $\mathrm{mL}$, and acetone: $n$-hexane $(1: 1, v / v)$ extraction mixture $(50 \mathrm{~mL})$ was added to it. The tube contents were thoroughly mixed/ stirred with a glass-rod for three minutes. The resultant mixture was centrifuged at a speed of 2,500 rpm for three minutes, and the supernatant was directly decanted into a 1 liter capacity separatory funnel. Then, 40 $\mathrm{mL}$ acetone: $n$-hexane (1:1) solvent mixture was added again to the same centrifuge tube, homogenized, centrifuged and decanted as previously in the same separatory funnel. Afterward, about $200 \mathrm{~mL}$ aqueous $\mathrm{Na}_{2} \mathrm{SO}_{4}(2.5 \mathrm{~g}$ per $100 \mathrm{~mL})$ and dichloromethane $(25 \mathrm{~mL})$ were sequentially added to the above separatory funnel followed by vigorous shaking for two minutes. After separating the phases, the lower dichloromethane layer was collected in a $250 \mathrm{~mL}$ 
conical flask. Using dichloromethane in two more $25 \mathrm{~mL}$ portions, the aqueous layer partitioning was repeated. The combined extract of dichloromethane was then passed through a glass column $(25 \mathrm{~mm}$ id $\times 450 \mathrm{~mm})$ over $25 \mathrm{~g}$ of anhydrous sodium sulphate to collect dry extract while the aqueous extract was discarded. Finally, $10 \mathrm{~mL}$ dichloromethane was used to wash the sodium sulphate column, and the combined extracts along with washings were concentrated upto $1 \mathrm{~mL}$ on rotary evaporator before clean-up.

\section{Clean-up process}

For clean-up, a $21 \mathrm{~cm}$ long polypropylene column $(1.2 \mathrm{~cm}$ id) was plugged up with cottonwool (pre-washed with dichloromethane), about 1 $\mathrm{g}$ anhydrous $\mathrm{Na}_{2} \mathrm{SO}_{4}$ was transferred over it, and then activated acidic alumina (about $4 \mathrm{~g}$ ) was added to column with continuous tapping to achieve compact packing. About $1 \mathrm{~g}$ anhydrous $\mathrm{Na}_{2} \mathrm{SO}_{4}$ was added again to the column forming a bed on the column top. The column was pre-washed with $5 \mathrm{~mL}$ dichloromethane with subsequent transfer of $1 \mathrm{~mL}$ dried dichloromethane extract to the column. About $15 \mathrm{~mL}$ of eluate was obtained using dichloromethane flow rate of $1 \mathrm{~mL}$ $\min ^{-1}$, evaporated to dryness, and resulting residue was dissolved in $n$-hexane $(0.5 \mathrm{~mL})$ prior to instrumental analysis.

\section{Quantitative analysis}

Auto injector was used to inject $5.0 \mu \mathrm{L}$ of dissolved residue to gas chromatograph. The areas under different peaks in the resultant chromatogram were compared with those obtained from respective standards injections, and instrument performance was evaluated based on linearity, percent recovery, repeatability and limits of detection and quantification.

\section{Results and Discussion}

Dioxins are 'persistent organic pollutants' that are extremely toxic, and humans are exposed to them mainly through food ingestion [1, 7, 22]. The present study develops a method to determine four different polychlorinated dibenzo-p-dioxins (PCDDs) congeners in wheat and rice samples.
The selected congeners were 1,2,3,7,8pentachlorodibenzo- $p$-dioxin (congener 1), 2,3,7,8tetrachlorodibenzo- $p$-dioxin (congener 2), 1,2,3,6,7,8-hexachlorodibenzo- $p$-dioxin (congener 3 ) and 1,2,3,4,6,7,8-heptachlorodibenzo- $p$-dioxin (congener 4). To determine PCDDs in rice and wheat grain matrix, the gas chromatographic method described by Khan et al. (2007) for pesticides analysis in grains was followed with some modifications [33]. For the quantitative analysis, the GC column was equipped with $\mu$ ECD. Initially, the PCDDs from spiked grain samples were extracted through 1:1 nhexane:acetone mixture. The propylene mini columns containing acidic aluminium oxide and anhydrous sodium sulphate were then utilized for clean-up to eliminate the possible residual fat and co-extractives from the sample extracts. Otherwise, inadequate clean-up of sample can cause fast deterioration of gas chromatographic system particularly ECD, thus ruling out reliable results because of resulting inaccuracies and decreased precision [34]. PCDDs generally show low water solubilities, and highly chlorinated PCCDs exhibit high hydrophobicity [35]. Thus, they usually accumulate in lipid fraction of biological samples, and a medium polarity solvent system (consisting of either one solvent or a binary solvent mixture) is often recommended for the extraction of PCDDs [36]. A study by Kooke et al. evaluated Soxhelt extraction efficiency of seven different solvent systems for PCDDs in fly ash and found benzene or toluene as most efficient extractant [37]. Literature shows the use of different solvents for the PCDDs extraction from various matrices prior to quantitative GC analysis, for example, $n$ hexane:acetone $(80: 20, \quad v / v)$ for fruits and vegetables [13], dichloromethane: $n$-hexane (1:1, $v / v)$ for fish, beef and corn silage [5], diethyl ether: $n$-hexane $(7: 10, v / v)$ followed by $n$-hexane for milk [38] and toluene for chicken eggs [29]. Most commonly applied solvent system is dichloromethane/ $n$-hexane; however, due to carcinogenicity and high cost of various solvents, and possibility of deterioration of detector $(\mu$ ECD), we recommend $n$-hexane/acetone as a better choice in the extraction of PCDDs. Sample extracts must be concentrated before clean-up or analysis, therefore the boiling point of solvent is important. After extraction, the sample extract is often 
partitioned with either one solvent or by using two separate solvents. Anhydrous salt (sodium sulphate or sodium chloride) can be added to absorb water so that the crude extract can be purified before subsequent partitioning step with a water immiscible solvent to avoid stable emulsion formation. Removal of any water from extract is also necessary prior to concentration.

The control and blank (solvent) were also run in order to assess the efficiency and purity of materials. No contamination peak was observed apart from two peaks emerged just after peak of solvent; however, those might not be characteristic of the congeners studied and might have appeared due to some impurity in the blank or matrix. The external standardization method was used for quantitative determinations. Accuracy is affected mostly by the capability of injecting exact sample amounts through a syringe. In this study a previously calibrated auto sampler was operated. Limit of detection (LOD) shows instrument sensitivity for selected congeners. Based on signalto-noise-ratio $(\mathrm{S} / \mathrm{N}) \geq 3$, the $\mathrm{LOD}$ value was determined as 0.002 and $0.005 \mathrm{ng} /$ injection for congener 1 and other three congeners (2-4), respectively. Under applied experimental conditions with constant $5 \mu \mathrm{L}$ injection volume, $x$ ng/injection $\approx 200 x \mathrm{ngmL}^{-1}$. The GC- $\mu$-ECD chromatograms of mixture of standard congeners (1-4) are illustrated in (Fig. 1 and 2) at $0.02 \mathrm{ng}$ and $0.10 \mathrm{ng}$ per $5 \mu \mathrm{L}$ injection of each standard congener, respectively. The figures show sufficient gas-chromatographic separation of four PCDDs with retention times of congeners $1,2,3$ and 4 observed at 13.0, 8.9, 19.2 and $29.4 \mathrm{~min}$, respectively. It is also evident from chromatograms that response of congener 1 is about double as compare to response of other three congeners, which is in agreement with its lower LOD. The sensitivity results suggest that the presented GC- $\mu$-ECD method has the ability to detect trace amounts of dioxins. Linear calibration curve was constructed for each selected congener as a plot of respective peak areas versus analyte concentrations under the proposed chromatographic conditions. (Table 1) presents derived calibration parameters for linearity test (linear range, correlation equation and correlation coefficient) for all congeners. Congener 1 shows linearity in the range of 0.0020 $0.1000 \mathrm{ng}$ /injection i.e., $0.4-20 \mathrm{ngmL}^{-1}$ with correlation coefficient $\left(R^{2}\right)$ value of 0.9989 . The other three congeners (2-4) reveal linearity within $0.0050-0.5000 \mathrm{ng} /$ injection $\left(1.0-100 \mathrm{ngmL}^{-1}\right)$ and $R^{2}$ in the range of $0.9976-0.9991$.

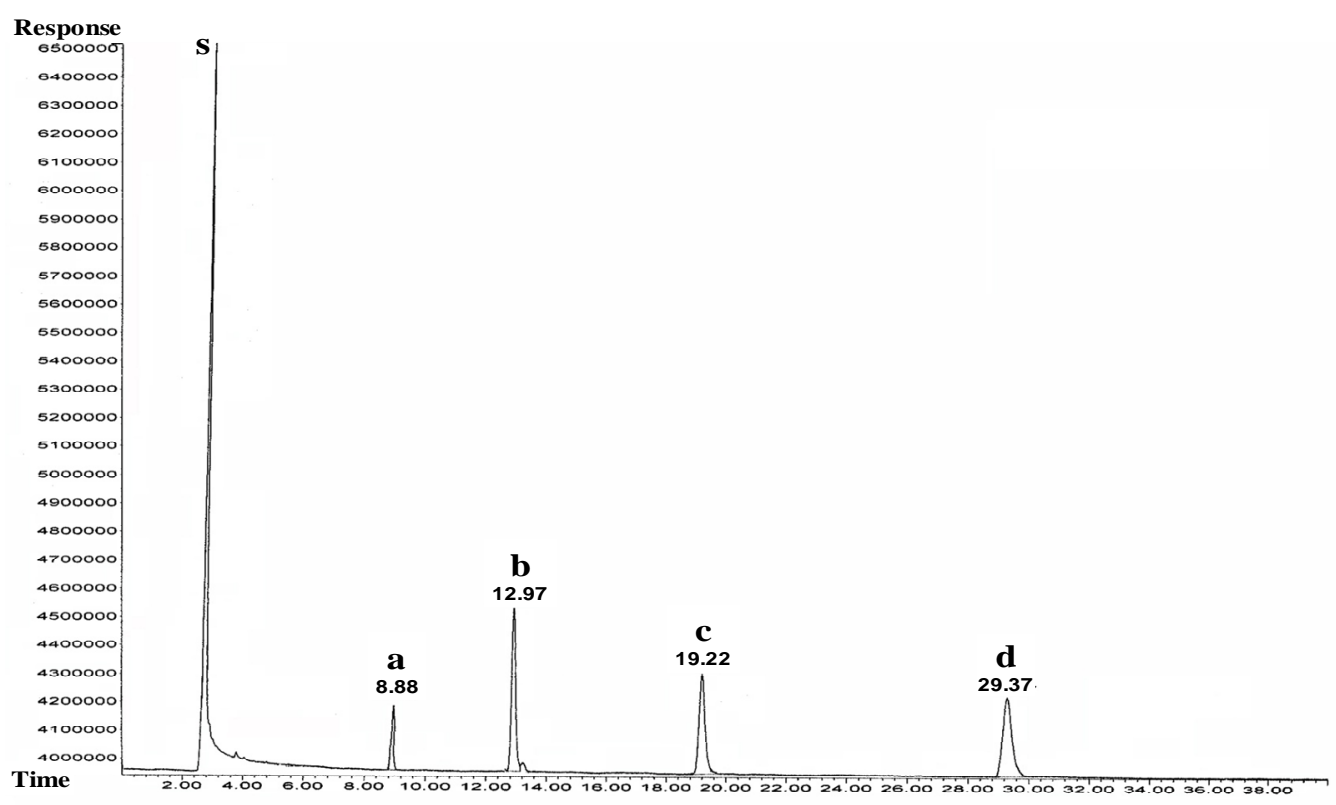

Figure 1. GC- $\mu$-ECD chromatogram for standard mixture of four PCDDs congeners (0.02 ng/5 $\mu \mathrm{L}$ injection). s: peak of solvent; a: congener 2; b: congener 1; c: congener 3; d: congener 4 


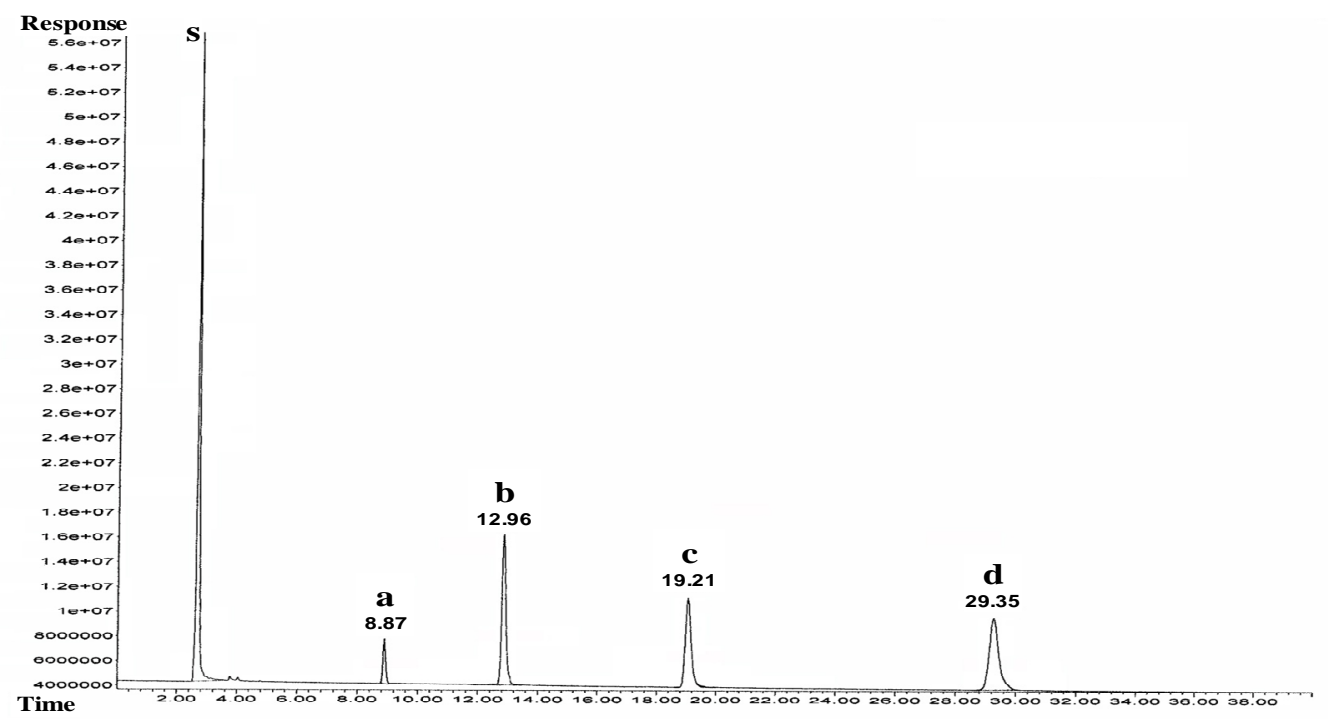

Figure 2. GC- $\mu$-ECD chromatogram for standard mixture of four PCDDs congeners (0.10 ng/5 $\mu \mathrm{L}$ injection). s: peak of solvent; a: congener 2; b: congener 1; c: congener 3; d: congener 4

Table 1. Statistical parameters for calibration of selected congeners.

\begin{tabular}{cccc}
\hline PCDDs Congeners & Linear Range $\left(\mathbf{n g} /\right.$ injection $\left.^{\mathrm{a}}\right)$ & Correlation Equation & Correlation Coefficient $\left(\boldsymbol{R}^{2}\right)$ \\
\hline $\mathbf{1}$ & $0.0020-0.1000$ & $\mathrm{y}=733.3+58882431 \mathrm{x}$ & 0.9989 \\
$\mathbf{2}$ & $0.0050-0.5000$ & $\mathrm{y}=808.2+16265950 \mathrm{x}$ & 0.9991 \\
$\mathbf{3}$ & $0.0050-0.5000$ & $\mathrm{y}=8765.9+23045998 \mathrm{x}$ & 0.9988 \\
$\mathbf{4}$ & $0.0050-0.5000$ & $\mathrm{y}=457.7+14346032 \mathrm{x}$ & 0.9976 \\
\hline
\end{tabular}

Based on correlation coefficient values from five point calibration curves, a reasonable linearity was demonstrated by all tested congeners. From the precision analysis of calibration data, the intra-day RSDs of peak areas $(5 \mu \mathrm{L}$ injection, 3 injections per day) for standard PCDDs solutions $\left(2 \mathrm{ngmL}^{-1}\right)$ were $8.1,2.5,3.3$ and $3.2 \%$ for congeners 1, 2, 3 and 4, respectively. Similar concentration $\left(2 \mathrm{ngmL}^{-1}\right)$ standard solutions of four congeners yielded inter-day RSDs of peak areas (5 $\mu \mathrm{L}$ injection, 3 injections per day $\mathrm{x} 3$ days) in the range of $3.1-10.6 \%$. The peak areas RSDs $<$ $15 \%$ indicate good repeatability of GC- $\mu$-ECD method. The instrument performance was also evaluated based on retention time shifts in repeated analysis. The percent RSDs of retention times for 10 successive $5 \mu \mathrm{L}$ injections of four congeners (2 $\mathrm{ng} \mathrm{mL}{ }^{-1}$ ) were ranged at $0.09-0.18$. During the whole study, the repeated analysis $(5 \mu \mathrm{L}$ injection, 10 injections per month $\mathrm{x} 13$ months) of standard congeners $\left(2 \mathrm{ng} \mathrm{mL}^{-1}\right)$ gave shifts in the retention times as follows: $12.28-12.95 \mathrm{~min}(0.06-0.19 \%$ RSD) for congener 1, 8.39-8.74 min (0.09-0.51\% RSD) for congener 2, 18.21-19.20 $\mathrm{min}(0.03-0.12$ $\%$ RSD) for congener 3 , and 27.85-29.35 min (0.02-0.07\% RSD) for congener 4. This data shows excellent repeatability of instrument and column (HP-5MS) performance.

The recovery percents in wheat and rice grains were examined at applied spiking levels of $0.02,0.05$ and $0.1 \mathrm{ng} \mathrm{g}^{-1}$ for congener 1 , while $0.05,0.1$ and $0.5 \mathrm{ng} \mathrm{g}^{-1}$ levels of spiking were set for congeners 2, 3 and 4. Limit of quantification (LOQ) of used method for both wheat and rice samples was observed as $0.1 \mathrm{ng} \mathrm{g}^{-1}$ in case of congener 1 and $0.5 \mathrm{ng} \mathrm{g}^{-1}$ in case of congeners $2-4$, based on $\mathrm{S} / \mathrm{N}$ ratio $\geq 10$. The reproducibility of spiking data was checked by three injections of each extract. The percent recovery and precision found at applied spiking levels for wheat and rice grains are listed in (Table 2 and 3), respectively. 
The GC- $\mu$-ECD chromatograms of spiked samples of wheat and rice are presented in (Fig. 3 and 4), respectively, at $0.1 \mathrm{ngg}^{-1}$ congener 1 and $0.5 \mathrm{ngg}^{-1}$ congeners 2,3 and 4 . Over applied spiking range, the average recovery of congener 1 was in the range of $85.96-120.74 \%$ and $95.32-116.88 \%$ from wheat and rice, respectively, with RSD range of $8.31-13.95 \%$. In contrast, the congeners 2,3 and 4 were recovered from wheat at their applied spiking levels in the average range of $87.70-115.54 \%$, $85.64-117.87 \%$ and $88.40-119.32 \%$, respectively, with RSD $3.99-10.82 \%$. The average recovery of congener 2, 3 and 4 from rice at applied spiking levels was in the range of 77.67-115.68\%, 83.18$119.68 \%$ and $79.76-131.15 \%$, respectively, with their RSD values in the range of 5.57-14.75\%. Interestingly, at lower spiked levels in all cases (i.e., $0.02 \mathrm{ngg}^{-1}$ for congener 1 and $0.05 \mathrm{ngg}^{-1}$ for other three congeners) the percent recovery values are greater than $100 \%$. It is because of the reason that the chance of error is often enhanced at lower residual concentration, but the stated results are well within the European Union (EU) permissible error range, i.e., within 15\% RSD [5, 39]. At LOQ, the average percent recovery of congeners $1-4$ for wheat was $85.64-93.59 \%$ with RSD $3.99-8.31 \%$, while for rice the average recovery of congeners 14 was $77.67-95.32 \%$ with RSD $6.29-9.88 \%$. The difference in recoveries and \%RSDs of PCDDs congeners in wheat and rice is due to different matrix effect. The given results reveal that the recovery of selected congeners by presented method is quite satisfactory with reasonably good reproducibility. Hence, the developed method can satisfy the requirement of monitoring PCDDs in wheat and rice samples.

Table 2. Applied spiking levels, percent recoveries and percent RSD values for selected congeners in wheat grains $(n=3)$.

\begin{tabular}{|c|c|c|c|c|}
\hline PCDDs & Congeners & Applied Spiking Levels $\left(\mathrm{ngg}^{-1}\right)$ & Mean \% Recovery & RSD \% \\
\hline \multirow{3}{*}{\multicolumn{2}{|c|}{1}} & 0.02 & 120.74 & 9.35 \\
\hline & & 0.05 & 85.96 & 10.82 \\
\hline & & 0.10 & 91.33 & 8.31 \\
\hline \multirow{3}{*}{\multicolumn{2}{|c|}{2}} & 0.05 & 115.54 & 10.79 \\
\hline & & 0.10 & 87.70 & 6.57 \\
\hline & & 0.50 & 88.79 & 5.07 \\
\hline \multirow{3}{*}{\multicolumn{2}{|c|}{3}} & 0.05 & 117.88 & 9.93 \\
\hline & & 0.10 & 85.83 & 4.79 \\
\hline & & 0.50 & 85.64 & 3.99 \\
\hline & 4 & 0.05 & 119.32 & 10.71 \\
\hline & & 0.10 & 88.40 & 7.40 \\
\hline & & 0.50 & 93.59 & 4.50 \\
\hline
\end{tabular}

Table 3. Applied spiking levels, percent recoveries and percent RSD values for selected congeners in rice grains $(n=3)$.

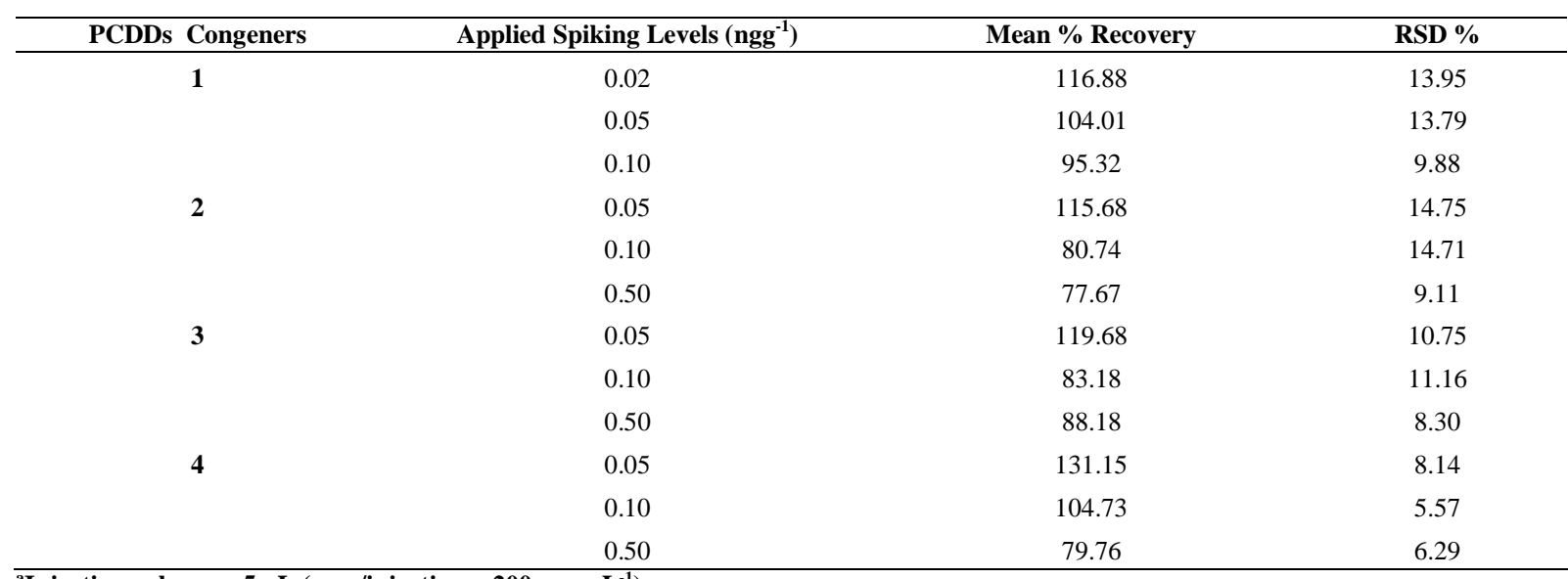

\footnotetext{
${ }^{\mathrm{a}}$ Injection volume $=5 \mu \mathrm{L}\left(x\right.$ ng/injection $\approx 200 x$ ngmL $\left.^{-1}\right)$
} 


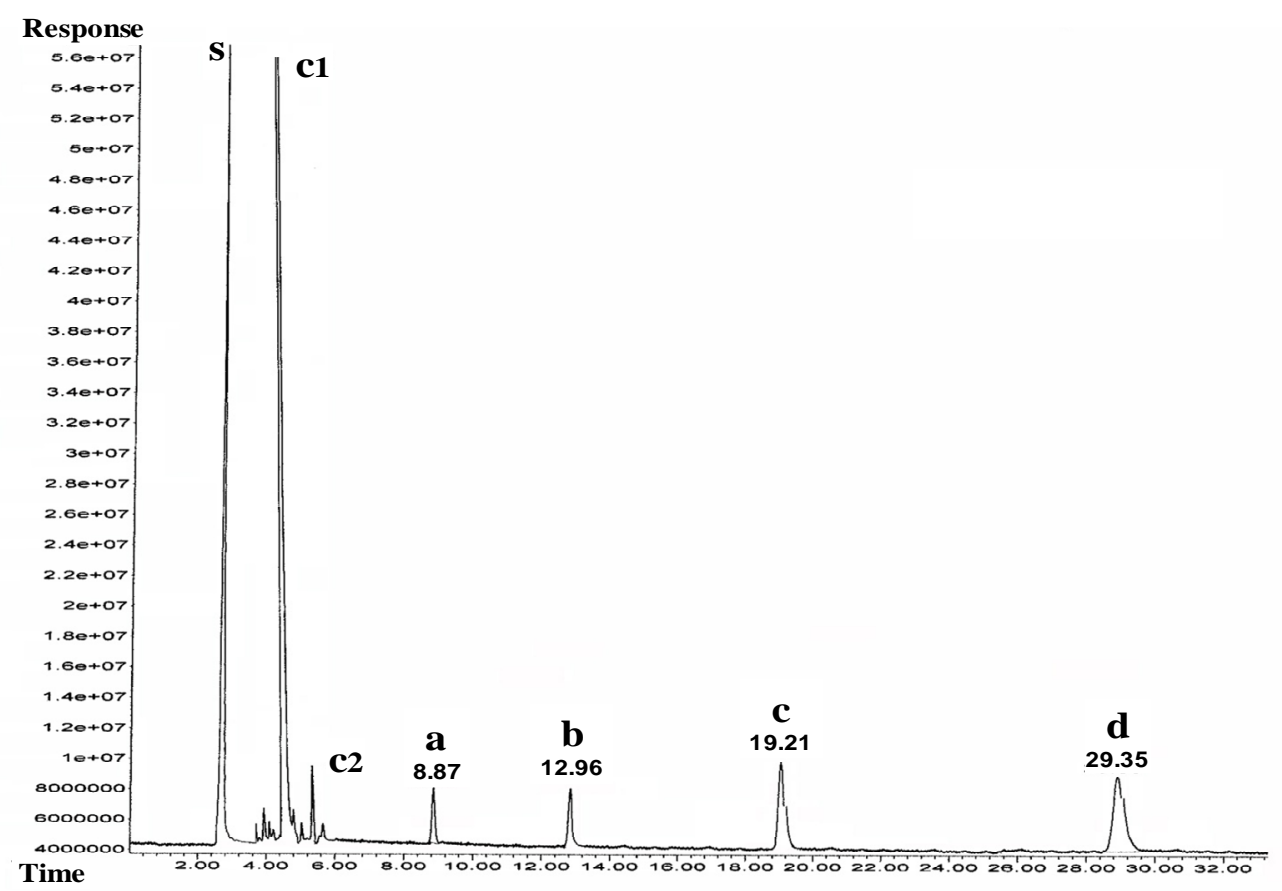

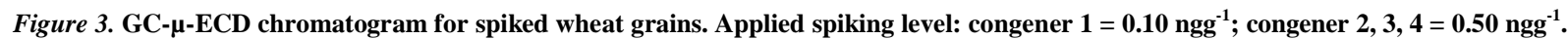
s: peak of solvent; c: contamination peak; a: congener 2; b: congener 1; c: congener 3; d: congener 4

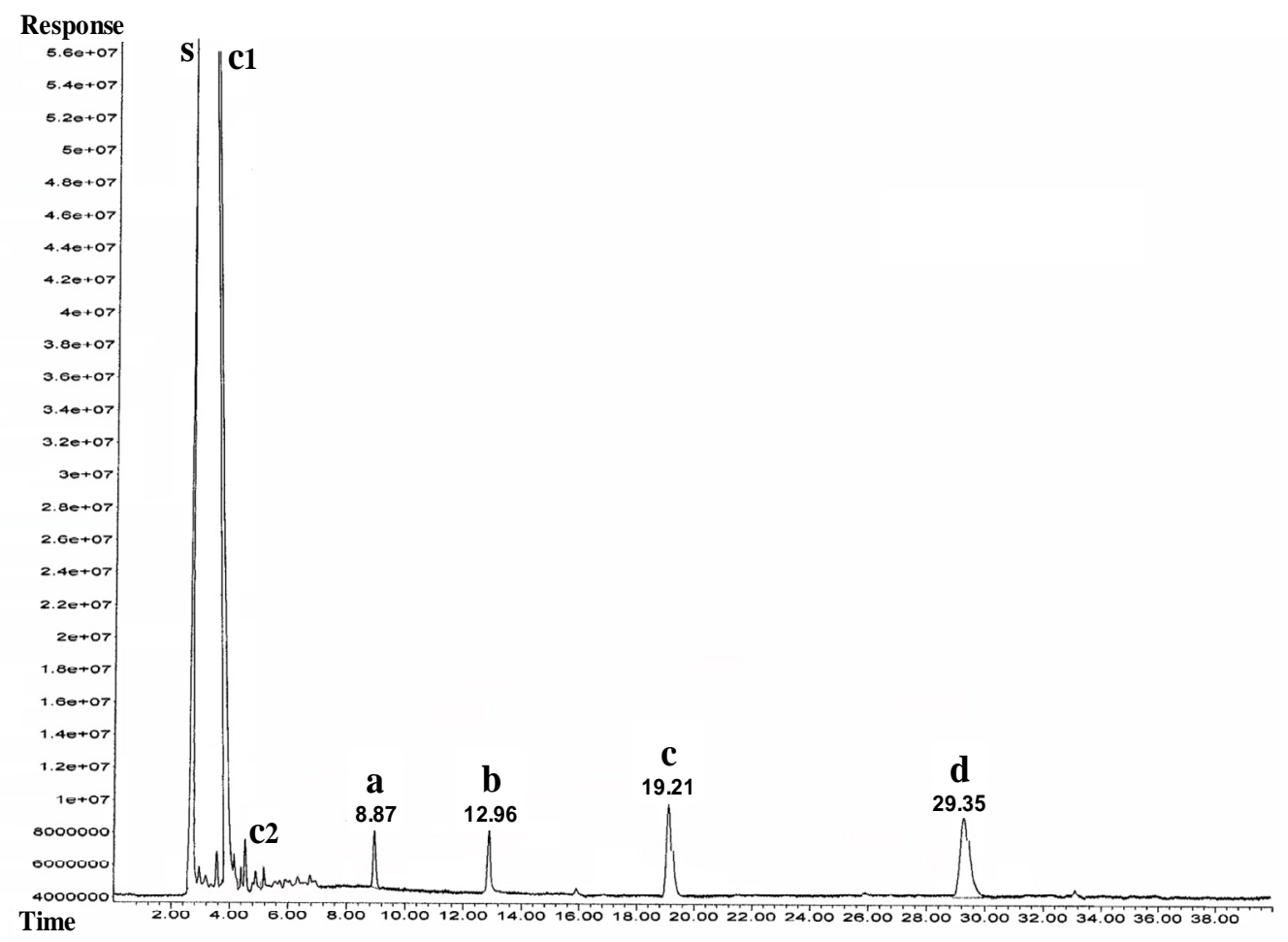

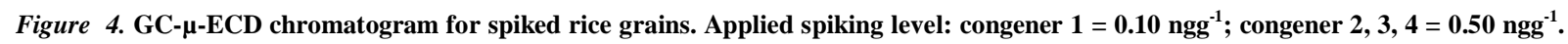
s: peak of solvent; c: contamination peak; a: congener 2; b: congener 1; c: congener 3; d: congener 4 


\section{Conclusion}

The current study has developed an inexpensive method first time in Pakistan to determine few basic congeners of PCDDs in wheat and rice grains. Present study focused on a simple operation, presenting a method with fair sensitivity and repeatability which is affordable by many researchers who cannot presently afford high resolution mass spectroscopy. However, this method, which implied simple bench-top GC- $\mu$ $\mathrm{ECD}$, is not suitable for studies requiring a limit of detection $<5 \mathrm{pg}$. The recommended tolerable daily intake for PCDDs (4 pg-TEQ/kg/day) is beyond the quantification limit of this method; however, the target can be attained by exploiting either automated and more effective clean up processes or more sensitive quantification, such as by 2 dimentional GC- $\mu$-ECD. Therefore, the developed method can efficiently provide screening and identification of four tested PCDDs with accurate quantification in samples, particularly the matrices heavily contaminated with dioxins, in routine analysis.

\section{Acknowledgments}

We greatly thank Pakistan Agricultural Research Council (PARC), Southern Zone Agricultural Research Centre, for essential scientific assistance on GC- $\mu$-ECD.

\section{References}

1. S. Kanan and F. Samara, Trends Environ. Anal. Chem., 17 (2018) 1. https://doi.org/10.1016/j.teac.2017.12.001

2. World Health Organization, Dioxins and their effects on human health (2016).

http://www.who.int/mediacentre/factsheets/f $\underline{\text { s225/en/ }}$

3. United States Environmental Protection Agency (USEPA). Learn about dioxin (2016). https://www.epa.gov/dioxin/learn-about-dioxin

4. G. C. Cakirogulları, D. Kilic and Y. Ucar, Food Control, 21 (2010) 1245. https://doi.org/10.1016/j.foodcont.2010.02.010

5. H. Sun, P. Wang, H. Li, Y. Li, S. Zheng, J. Matsiko, Y. Hao, W. Zhang, D. Wang and Q. Zhang, Sci. China Chem., 60 (2017) 670. https://doi.org/10.1007/s11426-016-9017-9

6. J. D. Urban, D. S. Wikoff, A. T. Bunch, M. A. Harris and L. C. Haws, Sci. Total Environ., 466-467 (2014) 586. https://doi.org/10.1016/j.scitotenv.2013.07.0 $\underline{65}$

7. Z. Lali, J. Pollut. Eff. Cont., 6 (2018) 1. https://doi.org/10.4172/2375-4397.1000215

8. T. Otani, N. Seike and T. Miwa, J. Food Hyg. Soc. Japan (Shokuhin Eiseigaku Zasshi), 47 (2006) 182.

https://doi.org/10.3358/shokueishi.47.182

9. G. A. Kleter, M. J. Groot, M. Poelman, E. J. Kok and H. J. P. Marvin, Food Chem. Toxicol., 47 (2009) 992.

https://doi.org/10.1016/j.fct.2008.08.021

10. L. R. Bordajandi, G. Gomez, E. Abad, J. Rivera, M. D. M. Fernandez-Baston, J. Blasco and M. J. González, J. Agric. Food Chem., 52 (2004) 992. https://doi.org/10.1021/jf030453y

11. G. Perello, R. Marti-Cid, V. Castell, J. M. Llobet and J. L. Domingo, Food Cont., 21 (2010) 178.

https://doi.org/10.1016/j.foodcont.2009.05.003

12. T. Tsutsumi, S. Takatsuki, R. Teshima, R. Matsuda, T. Watanabe and H. Akiyama, Chemosphere, 191 (2018) 514.

https://doi.org/10.1016/j.chemosphere.2017. 10.046

13. M. Esposito, A. D. Roma, S. Cavallo, G. Diletti, L. Baldi and G. Scortichini, Toxics, 5 (2017) 1. https://doi.org/10.3390/toxics5040033

14. A. Husain, B. Gevao, B. Dashti, A. Brouwer, A. P. Behnisch, M. Al-Wadi and M. AlFoudari, Ecotoxicol. Environ. Saf., 100 (2014) 27.

https://doi.org/10.1016/j.ecoenv.2013.12.002

15. Y. Wan, P. Jones, R. Holem, J. Khim, H. Chang, D. Kay, S. Roark, J. Newsted, W. Patterson and J. Giesy, Sci. Total Environ., 408 (2010) 2394.

https://doi.org/10.1016/j.scitotenv.2010.02.003

16. E. Bruns-Weller, A. Knoll and T. Heberer, Chemosphere, 78 (2010) 653. https://doi.org/10.1016/j.chemosphere.2009. $\underline{12.014}$

17. K. Srogi, Environ. Chem. Lett., 6 (2008) 1. https://doi.org/10.1007/s10311-007-0105-2 
18. A. Tard, S. Gallotti, J. Leblanc and J. Volatier, Food Addit. Contam., 24 (2007) 1007.

https://doi.org/10.1080/02652030701317293

19. N. Loufty, M. Furhacker, P. Tundo, S Raccanelli and M. A. Tawfic, Chemosphere, 66 (2007) 1962.

https://doi.org/10.1016/j.chemosphere.2006. $\underline{07.081}$

20. A. Bocio and J. L. Domingo, Environ. Res., 97 (2005) 1. https://doi.org/10.1016/j.envres.2004.01.012

21. A. Papadopoulos, I. Vassiliadou, D. Costopoulou, C. Papanicolaou and L. Leondiadis, Chemosphere, 57 (2004) 413. https://doi.org/10.1016/j.chemosphere.2004. $\underline{07.006}$

22. T. Huang, W. Jiang, Z. Ling, Y. Zhao, H. Gao and J. Ma, Sci. Rep., 6 (2016) 1. https://doi.org/10.1038/srep21997

23. J. K. McCrady, C. McFarlane and L. K. Gander, Chemosphere, 21 (1990) 359. https://doi.org/10.1016/00456535(90)90006-F

24. R. Uegaki, N. Seike and T. Otani, Chemosphere, 65 (2006) 1537.

https://doi.org/10.1016/j.chemosphere.2006. 04.009

25. G. Suzuki, M. Someya, H. Matsukami, N. M. Tue, N. Uchida, L. H. Tuyen, P. H. Viet, S. Takahashi, S. Tanabe, A. Brouwer and $\mathrm{H}$. Takigami, Emerg. Contam., 30 (2016) 98. https://doi.org/10.1016/j.emcon.2016.03.001

26. S. Li, G. Liu, M. Zheng, M. Wang, K. Xiao, C. $\mathrm{Li}$ and $\mathrm{Y}$. Wang, Chemosphere, 126 (2015) 73.

https://doi.org/10.1016/j.chemosphere.2015. 02.014

27. L. Rodenburg, S. Du, H. Lui, J. Guo, N. Oseagulu and D. Fennell, Environ. Sci. Technol., 12 (2012) 6612. https://pubs.acs.org/doi/10.1021/es300560q

28. L. Zhang, J. Li, Y. Wu and Y. Zhao, Chin. J. Chromatogr., 25 (2007) 887. https://doi.org/10.1016/S18722059(08)60007-3

29. International POPs Elimination Network (IPEN) Secretariat, Sustainable Development Policy Institute-SDPI (Pakistan) and Arnika Association (Czech Republic)
Islamabad-Prague, Contamination of chicken eggs near the dump site on the edge of Peshawar, Pakistan by dioxins, PCBs and hexachlorobenzene (2005).

https://www.researchgate.net/publication/27 7328134

30. A. Scheeter, J. R. Startin, M. Rose, C. Wright, I. Parker, D. Woods and H. Hansen, Chemosphere, 20 (1990) 919. https://doi.org/10.1016/00456535(90)90201-4

31. I. A. T. Khan and Z. T. Maqsood, Bull. Environ. Contam. Toxicol., 82 (2009) 722. https://doi.org/10.1007/s00128-009-9683-y

32. N. Khan, A. Inam, J. F. Mueller, T. Herrmann and O. Paepke, Organohalogen Compd., 66 (2004) 1420.

https://espace.library.uq.edu.au/view/UQ:10 $\underline{1225}$

33. I. A. T. Khan, Riazuddin, P. Zahida and A. Mubarik, Bull. Environ. Contam. Toxicol., 79 (2007) 454.

https://doi.org/10.1007/s00128-007-9266-8

34. Y. Zhang, J. Yang, R. Shi, Q. Su, L. Yao and P. Li, J. Sep. Sci., 34 (2011) 1675. https://doi.org/10.1002/jssc.201100058

35. A. Aberg, M. MacLeod and K. Wiberg, $J$. Phys. Chem. Ref. Data, 37 (2008) 1997. https://doi.org/10.1063/1.3005673

36. F. Bruner, J. Chromatogr. Libr., 20 (1981) 241.

https://doi.org/10.1016/S03014770(08)60135-9

37. R. M. M. Kooke, J. W. A. Lustenhouwer, K. Olie and O. Hutzinger, Anal. Chem., 53 (1981) 461. https://doi.org/doi:10.1021/ac00226a017

38. P. Korytar, C. Danielsson, P. E. Leonards, P. Haglund, J. de Boer and U. A. T. Brinkman, J. Chromatogr. A, 1038 (2004) 189. doi:10.1016/j.chroma.2004.03.026

39. P. Haglund, P. Korytar, C. Danielsson, J. Diaz, K. Wiberg, P. Leonards, U. A. T. Brinkman and J. de Boer, Anal. Bioanal. Chem., 390 (2008) 1815. https://doi.org/10.1007/s00216-008-1896-0 